\title{
Professional Development through Action Research: Case Examples in South African Higher Education
}

\author{
Margaret Fletcher and Ortrun Zuber-Skerritt \\ Faculty of Education, Griffith University \\ Brisbane, QLD 4111, Australia \\ Author to review proofs: \\ Margaret Fletcher \\ Faculty of Education, Griffith University \\ Nathan, QLD 4111, Australia
}

Tel: 61-7-3735 6869; Mob: 041 2147484; Fax: 61-7-3735 5965

E-mail: M.Fletcher@griffith.edu.au

\section{Suggested running head:}

$\mathrm{AR}$ for PD in HE

\begin{abstract}
:
This paper identifies the quality characteristics of a professional development (PD) program on action research (AR) and presents the results of a second-order evaluation of such a program. Three case examples in South African higher education demonstrate how AR methodology has been applied to design, conduct and evaluate the PD program and to identify new ways of learning and improving professional practice in higher education. From data analysis, we distinguish six factors significant in contributing to the quality of the PD program in all three universities: facilitator expertise, adaptive planning, responsive evaluation, critical events, application, and self-efficacy. On the basis of the evaluation results, we present five models: (1) the AR workshop cycles; (2) characteristics of a quality PD program; (3) a PD program on and through AR; (4) three levels of reflection on AR; and (5) meta-action research.
\end{abstract}

\section{Key words}

Professional Development in Higher Education; Meta-Action Research; South Africa; Second-order Evaluation. 


\section{Introduction}

Professional development is a significant issue in all workplaces for dealing most effectively with the complexity of modern society. Unprecedented technological advancement in recent times ensures that changing workplace demands and the need for currency of knowledge provide ongoing economic imperatives that professional development seeks to address. Professional development is therefore a costly part of what governments, professions, companies and individuals must do to operate most efficiently, in responding to contingencies and seeking to build platforms for sustainable growth in the face of continuous change. Internationally, focus on reform is grounded in the notion of economic prosperity and has inspired a range of systems-level aspirations for professional development to improve how people and organisations learn and thus their capacity to engage constructively with the complex issues challenging society at all levels (Senge 1990).

While most developed countries have an established history of professional development, in South Africa the skilling of the nation's workforce is relatively new and has major political, economic and social implications. Consequently, the South African government has adopted a range of programs and approaches designed to support political stability, economic growth and strong educational development. For example, the first African National Congress published A Policy Framework for Education and Training (ANC 1994) based on the principles of democratic participation, development of human potential and establishing a balance of access and power across the nation. This framework sought to redress the destructive consequences of the previous apartheid government's policies that deliberately tried to stifle intellectual development of the nation's majority black population in schools and higher education through racial segregation and unequal allocation of resources to students and teachers from the diverse ethnic groups vis a vis the white population.

Walker and Unterhalter (2004, 280) succinctly characterise this situation:

The past was that of apartheid South Africa - the richest country on the African continent and one of the most unequal societies in the world. Racially ordered oppression, gendered injustice and economic exploitation had been sustained through the construction of segregated cities, white farms and white suburbs, patriarchal social relations and a grossly inequitable education system.

Clearly, in the wake of entrenched apartheid the national education system has a vital role to play in reconciling the past with the present and in developing human potential across society to build a future of sustainable wellbeing, equality and justice for all South Africans. The greatest challenge for the education system in the post-apartheid era has been to re-educate teachers and students at all levels, to move from what (Freire 1972) described as rule-governed authoritarian 'instruction' and a 'pedagogy of the oppressed' to learner-centred approaches to teaching, reflective practice, action learning and participative action research as advocated by Fals Borda (1998; 2006) and Fals Borda and Rahman (1991). 
Although Freire's and Fals Borda's concern to emancipate the oppressed was initially in response to circumstances of the oppressed peoples of South America, their practical approaches can be applied to emancipation of oppressed peoples wherever they may be, including in South Africa and Australia. For example, Abraham (1994 a, b) demonstrates the practical application of 'exploratory action research' to the design of a professional management program for indigenous people in Australia, which Barry Richie, CEO of Mount Eliza Australian Management College, claims to be very similar to the programs that his college undertook for professional development in China (Abraham 1994b, book cover).

There has been considerable procrastination, resistance to change and even strong opposition to new forms of educational practice in developing countries, where education systems are so often instrumental in perpetuating the social, political and economic structures that sustain the oppressors. However in post-apartheid South Africa we also see encouraging innovations. In this paper we focus on professional development in higher education and management education (Blunt and Merrick 1992; Kiggundu 1991) and specifically on three related approaches that are particularly suited to the new context in South Africa: action learning (Revans 1991a), reflective practice (Reed et al. 2002) and action research (Walker 1996). By comparison with traditional education paradigms, these approaches are less power-oriented (yet they are powerful and empowering) and more democratic, participative, and culturally sensitive to diverse peoples in terms of their ethnicity, race, religion, language, gender and socio-economic background. They do not assume that the absence of academic credentials signifies inability for more advanced learning.

Action research is increasingly known and practised in South Africa in all sectors of society, especially in education, higher education, industry, government and community development. The focus has been generally on action and development and less on rigorous research; and so far there has been little evaluation research. In this paper we evaluate a workshop program that we conducted in 2005 on action research in three different university settings - two programs each of three days and the other a one-day program. Participants came from diverse disciplines in the human, social, health and management sciences and from all provinces in South Africa. There were about 30 participants in two of the universities and 12 in the third.

Here we aim to deepen understanding of action research as a means to engage critically with issues confronting the contemporary world. Our study helps to develop critical systems thinking and its applications through contributing to (1) knowledge associated with program development based on action research design; (2) evaluation of action research; (3) quality in action research; and (4) meta-action research. ${ }^{1}$ We use what Meynell (2005) termed a 'second-order approach' to evaluating and facilitating organisational change, learning and sustainable development. While first-order research is now recognised as imposing pre-determined measures for expected outcomes, secondorder research aims to find out 'what is important to those involved in the research and to

\footnotetext{
${ }^{1}$ We have minted this term to refer to what we see as our action research on action research.
} 
evaluate why the research might be meaningful to them' (Meynell 2005, 222). In other words, a first-order approach to evaluation is located in the positivist paradigm, and a second-order approach is informed by a non-positivist, phenomenological research paradigm.

To clarify, we begin by defining the following terms used in this paper: (non-) positivism, evaluation, value, monitoring, stakeholders, outcomes, action learning, action research and meta-action research.

Positivism is a belief that scientific methods can be used to construct 'objective' knowledge of reality, of 'the world as it really is', and that researchers can be detached observers of objective facts when they use these methods. Positivists claim that this kind of knowledge, which is one kind among others, is the only valid and legitimate kind (Chalmers 1982). Non-positivists in the social sciences offer an alternative view because they reject its premises as false. They argue that the human and social sciences require methodologies different from the natural sciences, since the nature, behaviour and mind of humankind constitute a complex whole that cannot be observed objectively by outside researchers. Non-positivists recognise that observations by humans cannot be neutral, objective or value free; rather they are subjective interpretations dependent on the observer's theoretical framework and value system. In this view researchers need to triangulate multiple perspectives from observers and 'participants' - rather than 'subjects' - in the research process (including the analysis and interpretation of data) to make the results as authentic and meaningful as possible to the people involved in the research as well to external observers.

Evaluation means to establish the value or worth of something. In the context of this project in universities in South Africa, our evaluation aimed at identifying the worth of a professional development program on action research for all stakeholders, and at better understanding how they valued the workshop experience.

Value is a subjective assessment of worth according to evidence that indicates the usefulness or otherwise of a program. It makes clear how this usefulness or otherwise is viewed by program participants. In our study we gathered this evidence through careful monitoring of participants' actions, reactions and achieved outcomes. We used secondorder approaches and formative evaluation as discussed below in Section 4.

Monitoring is a process that tracks progress to cumulatively record the effectiveness of the program in achieving its objectives to meet the stakeholders' needs.

Stakeholders are people who have a vested interest in the program's outcomes. Here they are the sponsors who organised and funded the program, the workshop participants, and the presenters.

Outcomes are results, or consequences of an event. Outcomes can be intended and shaped by the stated aims or objectives of a project, or they can be unintended, additional outcomes or unexpected side effects. Usually they involve a mix of both. Outcomes may 
be positive, resulting in valuable benefits to the stakeholders, or they may be negative where results are unsatisfactory, not related to the needs of stakeholders in the project, or may even be deleterious to the stakeholders.

Action Learning and Action Research have been defined in many different ways. Here we refer to an earlier definition (Zuber-Skerritt 2001, 1).

'Action Learning' means learning from action and concrete experience, as well as taking action as a result of this learning. Similarly, 'Action Research' is a cyclical, iterative process of action and reflection on and in action. ... The main difference between 'Action Learning' and 'Action Research' is the same as that between learning and research generally. Both include active learning, searching, problem solving and collaborative inquiry. However, action research is more systematic, rigorous, scrutinisable, verifiable, and always made public (e.g. in publications, oral or written reports).

Meta-action research is beyond the action research activities and processes. It is the highest level of conceptualising, abstracting and generalising the action research results through self-critical reflection - that is, it is action research on action research.

We argue that socio-historical factors in particular help to explain why action research has been popular in South Africa in recent years. As is true of action research in any location, here the skills and knowledge of action research need to be acquired through action learning and a collaborative, participatory, learner-centred approach to solving complex, real-life problems in the workplace. We provide evidence for our argument in three case examples, using multiple methods and analysing a variety of sources. These sources include documents, field observations and notes, interviews and qualitative surveys with sponsors and participants, and introspective analysis of ourselves as action researchers and as 'reflective practitioners' (Schön 1983).

We have assumed particular roles in reporting our experiences, work and research in South Africa in April/May, 2005. One author (Ortrun) has reflected on and reported her experiences as a facilitator in the professional development programs in this paper. The other author (Margaret) has evaluated the program as a critical participant observer in three universities in South Africa. Throughout the research process, we engaged in a critical dialogue with each other, challenging each other's assumptions and collaboratively questioning our evolving thinking in the light of our experiences and mutual feedback. Together, we developed models that derive from our thoughts and discussions.

Our model of evaluating the quality of a professional development program on action research and our conclusions offer a way forward in applying learner-centred teaching approaches to the traditional workshop/seminar context, using action learning to demonstrate action learning. Our model may also be applicable to other professional development programs and may usefully inform others who need to identify the salient 
features and characteristics of quality and relevance to the needs of their client(s), their institution or themselves as educators/facilitators.

Finally, we assume a critical reflective stance and re-conceptualise our experience as action researchers at three levels: the practical content level of a professional development program, the process level and the meta-action research level. While what we have termed 'meta-action research' is under-reported in the action research literature, we believe it has much to contribute to a transformative approach to research findings and to further development of both action research and evaluation of it. We demonstrate meta-action research in this paper through our use of action research to both evolve and evaluate a professional development program, using action research methodology to 'research' the program's value through responses of key stakeholders.

This paper is structured in seven sections and follows the process of each author researching and writing the first draft of a particular section. We then reviewed each other's sections, reflected on our interpretations, and discussed our conclusions.

- Historical background: Action research for South Africa

- The action research program

- Evaluation framework and methods

- Case examples

- Results

- Conclusions

- Reflections

\section{Historical Background: Action Research for South Africa}

The professional development program that is the focus of this paper was developed for South African senior managers, academics and postgraduates and has evolved over the ten years since it was introduced, with continuous feedback from participants. The original invitation from Stellenbosch University in 1995 was inspired by recognition of the utility of action research for learning and problem solving, so that the people of South Africa can themselves engage constructively with the complex issues confronting them at local, national and international levels. Program participants could see that Action Learning and Action Research (ALAR) offered a way forward as a methodology to address the change imperatives and maximise the opportunities for human development in a new South Africa and so initiated invitations for further workshops for professional development in action research in their own universities. The major impetus for these professional development programs was to improve the quality of learning and teaching in higher education, with a particular emphasis on supporting positive change in historically disadvantaged institutions. The aim was to enhance quality and increase quantity of research output and publications, and improve academic leadership and higher-degree supervision, recognising the capacity of the higher education system for a valuable multiplier effect. 
Here we focus on three recent academic staff development programs that we conducted in South Africa in April/May 2005. We maintain that action research has particular relevance in South Africa. Action research has considerable potential to contribute to development in a nation emerging from a history of colonisation, oppression, exploitation and under-development into a more democratic post-apartheid nation, with a quest for political, economic, cross-cultural and educational advancement and opportunity for all in a nation that values human equality. Action researchers - as change agents - can contribute to identifying positive ways to address complex problems in all realms of social, political and economic life.

However, we are also sensitive to issues of culture and realise that we as westerners have a different experiential background to the people of South Africa. We therefore acknowledge our limitations in the cross-cultural work we do and recognise our need to support a self-determining role for South African colleagues as they make significant changes in their lives especially in and through their professional work. They have their own informed understanding of what is most useful to learn and do, in order to further develop as professional educators and make valuable contributions to their society through advancement of learning and research. We work with them in this endeavour to facilitate processes of action learning and action research for the change and development they envision (Zuber-Skerritt 1996). As Revans $(1967,174)$ pointed out when he worked in several African countries using action learning:

Many of the development problems of Africa can be understood and treated only by those who share the culture of the African, who understand his (sic!) value system, his sense of fairness, his attitude to authority, and, what is often overlooked by the Western observer, what he wants out of life and what effort he is prepared to make to get it.

Kiggundu (1991, 34) reminds us that we do well to learn from the past. Before the colonisation of much of Africa, African people had no formal classroom instruction, and education for them was a process more like action learning.

It tended to be informal and took the form of apprenticeships. Most of it was onthe-job training with long periods of behavioural observations, tryouts, testing, coaching and feedback from elders and experienced observers.

Recognising this, it may be useful and reassuring for South Africans to return to that early successful system of apprenticeship and development initially through action learning, and then through action research.

\section{The Action Research Program}

The professional development program under review here does not operate from a bestpractice model of pre-existing professional knowledge and evidence bases. Our program proceeds from the assumption that each workshop will develop its own shape and life while involving the particular participants and their own experiences, knowledge, skills 
base and needs. Here, we agree with Wadsworth (2005, 81) when she revisits the difference between:

research which is conducted by human services professionals on, about and for their primary and ultimate beneficiaries - clients, patients, or community members - in contrast to research which is more for, by and with primary and ultimate beneficiaries. That is, the persistence of a model of professional expertise that presumes the applicability of prior knowledge developed from other professionals' research, in contrast to seeing professional expertise as lying in knowing how to develop that knowledge more from and with intended beneficiaries, constantly testing it with those beneficiaries for continued relevance at each new application.

(Emphases in original)

Our workshops on action research are typical examples that adopt a process-oriented, rather than a content-based approach to curriculum and professional development using action learning and action research processes. However, content knowledge needs to be available at the request of participants when needed. That is why scholars such as Bob Dick (2005) provide an archive and comprehensive resources on action research and related topics, including his internationally recognised course AREOL (Action Research and Evaluation Online), available at http://www.scu.edu.au/schools/gcm/ar/arhome.html (accessed 25 January 2007).

Content materials for our professional development program are usually provided to participants in print, on CD-Rom and/or by e-mail with references to other websites. A program schedule is suggested for each workshop and is negotiated with participants at the beginning of the session, after a needs analysis, and throughout the program. A brief summary of the content and essential aspects of the program can be found in Appendix I.

In this paper we discuss the evaluation of such a program of one or three-days duration that aims to introduce the basic concepts, principles and processes of action research to enable participants to conduct action research projects in their workplace through their own action learning processes and pathways.

In these short programs, we start with a needs analysis at the beginning of the workshop and simultaneously demonstrate a method and process that participants can first experience and then put into practice themselves in their teaching or consulting practice. The method, called 'Nominal Group Technique' (Willcox and Zuber-Skerritt 2003), is an effective and time-efficient tool for needs analysis and evaluation. The workshop takes about one hour, plus half an hour for analysis and report writing. The Nominal Group Technique works best with at least six and not more than 15 participants, and needs to be adapted for larger groups, e.g. splitting into groups of about ten members.

Since time is of the essence, we provide participants with all materials in written and/or electronic form before or at the beginning of the workshop, including references, papers, guidelines and handouts, power point presentations and activities. Participants then need 
not be distracted with detailed note taking, and can actively participate in the whole process of interactive presentations, discussions, reflections and feedback.

'Reflection' is developed consciously, deliberately and systematically through the introduction and use of a 'reflection diary' or 'research journal'. After each session, participants record what has been most significant for them, reflect on and write down their main learning points and what action(s) they will take in future to apply this learning in their work practice. Their reflections are then shared and used by the facilitator to adapt planning for the next session(s).

Another important principle in the program is achieving a balance between input, process and outcomes. This means our presentations - using power point, overhead transparencies (OHTs) and video - are always interactive, followed by activities and discussions in pairs or small groups. The results of these discussions are then shared with the whole group (orally, on OHTs or flip chart), before a new topic is presented and followed by the next cycle(s) of adaptive planning $\longrightarrow$ process $\longrightarrow$ outcomes $\longrightarrow$ input etc., continuously throughout the workshop, as shown in Figure I.

\section{Take in Figure I}

\section{Evaluation Framework and Methods}

Methods used in Meynell's (2005) second-order evaluation methodology include semistructured interviews, 'scheduled conversations' (such as pre-arranged informal meetings and phone or e-mail conversations), informative 'chance conversations' with members and associates of the sponsor organisation, attendance and participant observation, 'firstperson' reflections in a learning journal, and listening to participants' stories and their reflections on their experiences.

In our evaluation we used these second-order qualitative research methods, rather than first-order quantitative research methods, because the former are more appropriate to and in keeping with the basic philosophical assumptions of an emergent action research strategy. The main aims of action research are improved practice (the action part) and the participants' understanding, learning, insights and new knowledge, as 'practical theory' related to their workplace (the research part). Action research seeks to appreciate multiple perspectives and specificities of the participants' situations (Fletcher 2005). Therefore, second-order approaches to evaluating action research are more effective than first-order approaches; and formative evaluation (aiming to improve a situation or process) is more appropriate than summative evaluation (aiming to reach definite conclusions as to the effectiveness of a program in terms of the set objectives and intended outcomes). However, summative evaluation was used in one university where it validated the qualitative data (the original feedback report appears in Appendix II with permission to reprint it here). 
Furthermore, we sought feedback from several groups of stakeholders to identify the characteristics of a quality program on action research from multiple perspectives, i.e. from program participants, participant observers, sponsors, and the facilitator.

\section{Case Examples}

The professional development workshops were conducted in April/May, 2005 in three South African universities: Tshwane University of Technology (TUT) in Pretoria, an institution in a historically disadvantaged, black community; The University of the Free State (UFS) in Bloemfontein; and The University of Stellenbosch (US). Although US and (to a lesser extent) UFS are known to be 'white' universities, they had invited participants (academics) from historically disadvantaged institutions from all provinces and from other African countries. There was a balance of ethnic and gender representation among participants.

\subsection{Method}

Action research methods were used in design, conduct, evaluation and review of the workshops in response to stakeholders' feedback. Thus action research methods provided a systematic and rigorous evaluative role, with participatory action research data informing the evaluation. We believe that involving all participants as co-researchers during and after the workshops recognises the collaborative nature of research designed to achieve shared understandings and the capacity of all participants to contribute.

We have analysed indications of the learning process, interactions and documented outcomes of this professional development program across the three universities, in our effort to understand what characteristics contributed to the value of the program and why these features were relevant to program stakeholders in South Africa. We also invited the sponsors to respond to our findings in the light of their own perceptions of the workshops and stakeholder feedback.

Results reported here are based on evaluation of the three presentations of the program conducted over three days at two sites and over one day at the third site. The three sets of evaluation data enabled triangulation of evidence where we compared the data to identify similarities and differences across the three institutions. One of the authors, as the participant observer and evaluator, systematically collected data from participants through interviews, surveys, observation, audio and video recordings, and used these data to inform the action research process of 'review, reflection, rethinking and reinterpretation of taken-for-granted knowledge’ (NSDC 1995, 2).

During the workshops participants were encouraged to use a 'reflection diary' ('log book' or 'research journal') to record significant workshop events, reflect on their learning from these events and identify future action(s) to take in their workplace or elsewhere as a consequence of this learning. They were also invited to give feedback after each session through small-group discussions and reporting the results back to the whole group. These 
group reports were video recorded. More often than not, this feedback was used immediately to replan the next session.

The evaluator took notes while observing each session and between sessions interviewed several individuals by asking probing follow-up questions and recording the interviews on audiotape. Since these workshops were residential, we also had the opportunity to receive feedback in informal discussions over tea/coffee, lunch and dinner.

At the end of each day, the two authors held a briefing session to reflect on what went well, what didn't, and why. At the conclusion of each program, participants were asked to complete an open-ended questionnaire with three questions about what they found to be the positive and the negative aspects of the workshops and their suggestions for improvement.

\subsection{Analysis}

In an effort to manage the large corpus of information collected, we summarised and categorised the data as we moved recursively from one data source to another. Using the inductive analytic process that Yin (2003) described as pattern matching, we systematically compared findings to establish converging or diverging evidence from various sources. Pattern matching was used to identify chains of evidence in the data that established consistent and repeated themes. As we identified themes, we tentatively coded the categories in a matrix, gradually building an understanding of what constitutes quality in the professional development programs and how this contributes to the participants' learning. In this way we created what Strauss and Corbin (1997) call grounded theory.

The evolving and recursive nature of qualitative data analysis meant that we continually revised coding as progressive interpretations of the data became more distilled and representative. The development of categories reflected Lincoln and Guba's (1985) description of the process. As new insights emerged, coding was refined by 'filling in' or adding categories. We revisited data to 'extend' or re-interpret meanings when viewing the data from a different perspective. This new perspective resulted when we identified a new relationship or category, which caused us to re-think our original interpretation. The analytic progression in this research followed Miles and Huberman's (1994) use of matrices to systematically analyse, categorise, and display information as constructed from the data which we report in the following section.

Importantly, we used 'participant confirmation' and stakeholder validation by seeking feedback on our interpretations from participants and the three sponsors before finalising the results.

\section{Results}

Based on our data analysis, we distinguished six factors that were significant in contributing to the quality of the professional development programs in all three universities. These were facilitator expertise, adaptive planning, responsive evaluation, 
critical events, application and self-efficacy. Results reported here are supported with selected verbatim comments that typify responses from stakeholders.

\subsection{Expertise}

First, the facilitator's expertise was a factor evident in all the evaluation data analysed. Respondents identified expertise as the credibility of the facilitator as an action researcher, evident through her in-depth conceptual and applied knowledge, her skill in presenting this knowledge, and the quality of materials provided.

Participants described these qualities when evaluating the facilitator's workshop content and the processes used. Here are three typical comments from participants:

- The whole workshop was superb! I did not know a lot of ALAR!

- The whole workshop was wonderful and well presented.

- I enjoyed the manner in which the workshop was presented.

The process of small-group and large-group learning connected with participants as they positively evaluated the blending of formal explanations and discussion in group activities as opportunities for interaction, networking and learning from each other. For example they appreciated the facilitator's:

- Explanation of terminology and processes with applications in a group in the workshop and followed by feedback to reflect and listen to the ideas and input of the bigger group.

- Focus of involving those who already know 'the lived experience'.

However, several comments suggested a need to re-organise group activities:

- Give more time for group work with a facilitator at each group.

- (It was) quite disturbing to move from group to group.

- Moving from group to group - just as you start 'rapport', you have to move on.

One respondent reported her own problems encountered in the group work:

The frustration that I had concerned the following: The audience had different levels of experience in the field of research. In the larger group, the more experienced participants shared their experience in a practical useful manner from which I could learn. Unfortunately in one of the smaller groups one of the participants treated me as if I was one of her Master students who needed to defend my research proposal. I did not see the necessity to defend my proposal or to inform her that my proposal was already accepted by an outside university. I know that this was an isolated incident but it was very unpleasant. I suggest that you consider to target a specific group for training, e.g. novices and to train the more advanced researchers separately to address their specific needs. 
While this was an exceptional response, and the experience described did not diminish this participant's overall experience of the workshop, her comment highlights an issue related to the background and experience of participants, especially in terms of perceived and actual power relationships between them. A lesson for us as facilitators is to recognise that perceptions of unequal power can interfere with established roles we may assume to be in the spirit of supportive, 'critical friends'.

The facilitator's credibility as an action researcher was evident as participants watched her apply action research methods and demonstrate processes that contributed to the participatory knowledge construction of the group. Participants saw her as an expert in the field and an expert facilitator in organising interactive activities that enabled participants to explore complex concepts related to the topics presented. Respondents described such attributes as 'experience', 'a master of her subject', 'her passion and knowledge', 'professional', 'enthusiastic' as factors that contributed to their own learning. For example, they reported:

- $\quad$ The opportunity to learn from a knowledgeable person.

- Everything was useful. Power packed session.

\subsection{Adaptive planning through responsive evaluation}

The program content was based on an adaptive planning approach informed and moderated throughout by responsive evaluation - co-dependent characteristics that had a reciprocal effect on the approach taken in the workshops. Adaptive planning emerged as an important characteristic of the program, with 'choose your own adventure' or 'pick-apath' flexibility available for tailoring content to meet the changing interests and needs of participants. Ongoing monitoring of participants' developing understandings informed the content focus of the next session. The scope and sequence of content were adapted in response to the participants' requests and to an action-research approach that guided the delivery of the material. While all three implementations of the program were based on developing participants' understanding of action research in a range of learning contexts, the different deliveries did not follow the same sequence of topics. The common starting point for the program each time was a needs analysis where the facilitator used a nominal group technique (Willcox and Zuber-Skerritt, 2003). This was a deliberate strategy designed to frame the workshops within a culturally sensitive environment in which participants identified individual areas of need that contributed to a shared understanding of how the workshop would proceed. This technique was rated positively by respondents who perceived it as 'practical', 'useful' and 'great application', but with one exception: 'It was a waste of time and not relevant'. Other participants identified how they could apply this technique to their own work. For example:

- Powerful technique to gain authenticity in an assessment.

- [I found it] very interesting and effective in identifying and ordering priorities. 
- I was encouraged to use it in class to improve participation and interaction.

Throughout the workshops the cumulative effect was a guided, flexible learning experience for all participants. This flexibility was possible because we had integrated within each program a deliberate application of action research in the form of ongoing responsive evaluation. This enabled the facilitator to receive and act on feedback from participants throughout the workshop.

\subsection{Critical events}

Respondents identified what were for them critical events that contributed to their own learning. Their responses indicated that they had connected the content of the program to their own work in ways that they found personally and professionally meaningful and relevant and so the identified events varied across groups. Respondents specified moments in the workshops where their learning was significant and transforming. Some described these events as triggering a new understanding that challenged their knowledge or perspective, or as a moment that forced them to modify their view of themselves as researchers.

- I learnt to look at research from a different perspective. Not to just absorb everything like a sponge but to actively question things continuously. Good workshop and also very much applicable to myself as a researcher.

- (I learnt) that $A L$ is learning about life. That it is actually a non-academic learning and applying it in academia is merely one part of life, work etc. where we use it.

- We often think the small pebble on the beach is all the ocean is about.

[Note: This last comment refers to Reg Revans (1991b) and his metaphor illustrating the limitations of human knowledge and understanding in front of the 'wide ocean of our ignorance']

Others identified specific parts in the program that were personally significant. These included the video with 'Reg Revans' and the strategies relating to the 'Reflection Journal', 'Figure Eight Model' and 'Publication Syndicates'.

For students and those participants who were new to the concept of action research, several common areas were identified as significant. For example, clarifying the terms action research and action learning was an important starting point for this group. The following comments exemplify these moments:

- To finally understand what $A L$ and $A R$ are.

- Understanding the process of $A R$ and $A L$, and highlighting the differences between the two.

- Being introduced to ALAR was exciting and very valuable. 
- Everything to me was critical. This workshop assisted me to be clear in my thinking and to merge all the knowledge from Research, Teaching Methods and Psychology.

These evaluation results show how important it is to build 'reflection' into a PD program. Here we see the value of introducing the method and use of a 'reflection diary', to facilitate the process of reflecting on and learning from significant events and enhance participants' critical self-awareness through the learning and research experiences.

\subsection{Application}

A fourth characteristic was evident in participants' responses and their recognition of ways to apply the program's content to their own work, and in some instances to their own lives beyond work. Respondents talked about the relevance of content and process in ways that demonstrated congruity between the practices discussed in the workshops and their new understandings. They identified the applicability of workshop content to both their professional and personal lives, as the following quotes indicate:

I am excited about how the workshop opened up my eyes and provided me with operational tools so that I can seize these opportunities as a staff developer.

- Publication syndicates and how this idea has blossomed in other aspects of my life as well as academic - especially my creative side.

- 'Networking' - increasing academic and social cycle into the AR - has set an insight into doing my own project.

We could say that the applicability of the program to both work and non-work situations further underscores the effectiveness of the workshops in recognising the culturally diverse needs of the participants.

\subsection{Self-efficacy}

All of the above factors contributed in some way to the respondents' own perceptions of themselves as teachers, students or researchers. Three months after the workshop program, they commented on their renewed energies, willingness to 'have a go', and confidence in moving forward in their work or studies. For example:

- We have started an action research group in the School of Health Technology to implement an assessment model in the School.

- I again applied the Nominal Group Technique with great success in my July lecture in the module 'Professional Development as Researcher'. In my planning for next year, a full section on Action Research will be included in the module. I am also in the process of adapting our Research Planning Guides I and II for possible improvements after being introduced to Ortrun's 'scaffolding process' for the planning of theses and dissertations. 
Self-efficacy is a culture-specific outcome that is likely to be described differently across contexts and cultures. As we were particularly interested in evidence that demonstrated post-workshop effects in the South African context, we collected data from the sponsors three months after the workshops. For example, the sponsor at UFS wrote:

At least two of the students (PhD level) testified afterwards that they at last got some light in their action research projects. Their professional growth has since become obvious in the ways in which they are approaching their studies. One of them is now applying an adapted 'Figure Eight Model' in the replanning of her model for successful online/blended learning at the UFS. The other one chose the process enneagram as the basis of planning and developing a new postgraduate sport physiotherapy programme. A third PhD student who attended the workshops has been working on the proposal for a study within the AR paradigm that aims to develop a Service Learning model for Industrial Psychology students that can enhance learning in a transformed academic world in South Africa.

This feedback is evidence of the workshops' influence on participants' self-efficacy and actions taken as a consequence of their learning and continuing professional development during and after the PD program. It also alerts us to the broader efficacy of professional development beyond self, as evident through the multiplier effect of the three new university programs - an online/blended learning program, a new postgraduate sport physiotherapy program and a Service Learning model for Industrial Psychology students - mentioned in these examples.

\subsection{Discussion of results}

These evaluation results indicate that quality professional development programs are the result of a complex set of factors that contribute to a learning experience that is enabling and empowering. These factors are interdependent and work together. The workshop needs to be designed in a way that allows integration of flexibility, responsive evaluation and adaptive planning.

Figure II below summarizes those factors we have identified in the data as important characteristics of a quality professional development program.

Take in Figure II

While the facilitator's expertise was identified as a significant factor in the success of the professional development program, this success was sustained through careful monitoring of participants' needs and responding to these needs directly. Generally, this was done effectively in the light of the constructive responses received in interviews, surveys and email communication. However, integrated evaluation during a workshop will not guarantee access to all participants' views. A small but important set of respondents identified group work as problematic in the summative evaluation survey. This highlights the limitations of summative assessment where we were not able to respond to this issue. 
As action researchers, we know it is never too late to learn, and as we reflect on this we shall seek to find ways to overcome or at least minimise this problem when next we present the program.

The needs analysis at the beginning of each program served a dual purpose. First it provided the facilitator with information about participants' needs and expectations, which enabled initial adaptations to the program sessions. Second, it demonstrated a process and technique that participants could experience and apply in their own practice. Adaptive planning thus resulted in a meaningful program with sessions that provided critical events and transformative learning experiences for participants, so that they could apply their newly gained knowledge to their work, studies and in some cases to their personal lives. Continuous responsive evaluation integrated throughout the workshops ensured that participants developed the knowledge, skills and understandings that they needed for developing confidence and self-efficacy as action learners.

An important outcome for any program is sustainable learning that equips participants with the skills and confidence to test their new understandings in their own workplace. In the program reported here, participants acted on the content presented during the program and demonstrated the knowledge they had gained through initiating practices relevant to their own aims and needs when they returned to work. Clearly, they had become aware of their own roles in the learning process; they had learned about learning.

\section{Conclusions}

In this paper we have discussed how a professional development program on action research has been developed over time to meet the needs of a variety of clients/learners. We have also demonstrated how the quality of such a program can be evaluated using a meta-action research approach and qualitative research methodology to 'research' the value of the program - its strengths and weaknesses for stakeholders, and other possible outcomes - and improve both content and delivery .

So far we have presented two models, each based on our experience, participant observation and data from the three case examples with academics and postgraduates in South African universities. The first model (Figure I) illustrates the continuous cycles of adaptive planning (AP) $\rightarrow>$ input (I) $->$ process and critical reflection (P) $\rightarrow>$ outcomes (O) used throughout the professional development workshops, so that participants could learn, understand and actually experience the whole process of action learning and action research.

The second model (Figure II) summarises those factors we have identified in our data as important characteristics of quality in the professional development program. They are:

1. The facilitator's expertise with regard to credibility and international reputation, in-depth knowledge in the field, facilitation and process management skills, and the quality of the program materials; 
2. The facilitator's use of adaptive planning after a needs analysis at the beginning of the program and after each module or session, using:

3. Responsive evaluation based on constant feedback from participants to enable the facilitator to act on it immediately;

4. Critical events that contributed to participants' transformational learning and understanding of the new research paradigm;

5. Their ability to recognise ways to apply the program's content to their own professional and private lives; and

6. Their self-efficacy, enthusiasm and confidence in conducting action research after the program.

We can now summarise our findings and conclusions in a third model (Figure III) that shows the whole process of a professional development program on and through action research, including pre-workshop planning, the cyclic workshop model, and formative and summative evaluation.

\section{Take in Figure III}

This program was evaluated in all three university settings throughout the one and three days of workshops. This approach to evaluation enabled the facilitator to adapt the program constantly to the participants' needs (formative evaluation); and at the end of the workshop identify more generally and through first-hand experience what constitutes a quality professional development program on action research (summative evaluation). There were, as may be expected, limitations on the extent to which we could evaluate the real impact of the program on the participants and their institutions in the long term due to the poor response to our qualitative e-mail survey after three months - a well known problem in follow-up evaluation.

Our experience and evaluation of the three case examples indicate that action research:

- Resonates with and complements the changing role of professional development in building the new South Africa by promoting principles of equity, quality, and social and economic development;

- Connects people, practice and professional development;

- Facilitates inclusion, openness, critical review, transformational learning, change, new knowledge, growth, and personal and professional development;

- Provides multiple pathways that are personally meaningful;

- Can be learned by people in a professional role who want to be change agents.

The action learning principles and processes used in this professional development program - specifically on the topic of action research and designed for South African academics and postgraduates in higher education institutions - may have relevance to other professional development programs more generally, or may be adapted to particular situations and cultures. A meta-action research approach to conducting and evaluating action research programs can yield useful insight and capacity for tailoring and 
improving programs, as our example demonstrates. Thus use of meta-action research in this way is therefore a topic for further research and development.

\section{Reflections}

Preparing this paper has contributed to a reflective process as the authors have engaged with each other in reflective dialogue throughout the writing process. Several critical events have stimulated our reflections at a meta-action research level where we are doing action research on the action research by ourselves and others, at the highest level of conceptualising action research through self-critical reflection.

Our findings reported in the previous sections and summarised in Figure II, became one source for re-conceptualising our understandings of professional development through action research in South African higher education. Other critical events in the form of constructive feedback provided a lens for re-viewing our paper from a meta-analysis perspective.

What follows from here is a result of our meta-action research. We came to understand that action research can be conducted on at least three levels as shown in Figure IV below.

\section{Take in Figure IV}

The first level of reflection on action research refers to the conduct and practicalities of the professional development program on action research and to the actual activities grounded in experience and observation.

On further reflection about 'what worked and what didn't work' in our action research, we arrived at the second level, evaluating the processes we used. This level of reflection is grounded in the formative and summative data.

With increasing critical self-reflection on the first and second levels, we arrived at a meta-level of action research and re-conceptualised our previous interpretations to arrive at a more generic level of conceptual understanding as to what constitutes a successful, quality professional development program on and through action research. This model presented in Figure $\mathrm{V}$ below is a further refinement of our meta-action research and is potentially applicable to other change programs.

\section{Take in Figure V}

Our reflections in this final section are the result of meta-action research situated beyond the action research activities and processes reported previously. To make sense of our thinking we needed to substantiate our critical self-reflections. We found this confirmation through one of the most significant facilitators of change in South Africa: the venerable Nelson Mandela. 
Our findings of what constitutes an effective change program (Figure II) reminded us of Mandela's life history. If the qualities of credibility, knowledge, presentation skills and process management are seen to signify the expertise of a program facilitator, how can this be transformed to new understandings of what constitutes 'expertise' (problematising the results). Traditional western understandings of academic credibility are based on a person's credentials, publications and scholarly reputation. However, in developing countries credentialing may be experienced differently, through tangible successes rather than research successes. Publishing may be the result of oral dissemination and recognition of achievements. For example, during Mandela's imprisonment, his actions to facilitate change were articulated and disseminated across the globe in spite of efforts to silence him.

Mandela demonstrates in-depth knowledge as wisdom in action. He was able to endure, to take risks and make clear decisions that were instrumental in bringing about transformation and success. We may conclude that regardless of the field (an academic discipline, politics, action research etc.), the facilitator's presentation skills (actions) depend on his/her commitment, values, and conviction concerning the content of the message. Unless the facilitator can manage processes to engage participation and collaboration, their actions and message will have minimal impact.

Our research has identified significant factors that contribute to achieving the ultimate goal of any professional development or change program: needs analysis, adapting the program accordingly, critical events, and application to other workplace practices. These factors result in self-efficacy through responsive evaluation and adaptive planning and, in the case of our professional development program at three South African universities, in the much further reaching efficacy across society through the multiplier effect of improved teaching and research. On reflection, these significant factors highlight the utility of action research for dealing with the complexity of transition in post-apartheid South Africa through the higher education system for the benefit of individuals, organisations/institutions and ultimately for society at large.

In the light of our evaluation, we can now re-conceptualise change programs and processes returning to our Mandela example. With reference to Figure II, Mandela's life journey has been engaged in facilitating change to bring about racial equality. Indeed, Mandela's life project has been nothing less than to transform the South African nation to liberate the nation's indigenous people from the oppression of entrenched apartheid. During his time in prison, Mandela was able to identify the primary need of his country (freedom for all its citizens), how to adapt his actions accordingly (non-violence), how to recognise critical events, and how to respond to them in ways that were applicable outside the prison context (non-compliance). These characteristics of what was effectively a quality change program resulted in much more than a sense of efficacy and empowerment for Mandela and others, since these capable, committed and inspiring people eventually brought the downfall of apartheid and re-claiming of their country by the black peoples of South Africa. 
Here we have demonstrated the use of action research and meta-action research for professional development, a qualitative approach to improving teaching, learning and research through inclusive, collaborative processes. Through our research reported in this paper and our transformed understandings of ways in which a quality change program may embrace diversity to respond most effectively to human need, we hope to have contributed to a new niche of understanding that extends action research to a meta-level, and has relevance and applicability to any geographical, cultural or other context.

As our discussion in this paper makes clear, we recognise the intrinsic value of action research in critical systems thinking. We believe that our examples to improve professional development and evaluate these programs in South African universities demonstrate the utility and adaptability of action research as an inclusive approach to change, for self and for social efficacy. It is clear to us, and certainly to ever more who are involved in higher education in South Africa, that action research can make valuable contributions to a more equitable and stable society, particularly in these times of unprecedented technological transformation.

\section{References}

Abraham, S. (1994a). Board management training for indigenous community leaders using action research: The Kuju CDEP learning experience, Port Lincoln Kuju CDEP Inc., South Australia.

Abraham, S. (1994b). Exploratory action research for manager development, Action Learning, Action Research and Process Management Association (ALARPM), Brisbane.

ANC - African National Council (1994). A framework for education and training. Available at: http://www.anc.org.za/ancdocs/policy/educate.htm (accessed 25 January 2007).

Blunt, P. and Merrick, L. J. (1992). Managing Organizations, Walter de Gruyter, Berlin/New York.

Chalmers, A.F. (1982). What is This Thing Called Science?, University of Queensland Press, Brisbane.

Dick, B. (2005). Making process accessible: Robust processes for learning, change and action research. DLitt. International Management Centres Association. Buckingham (UK). Available at: http://www.uq.net.au/ zzbdick/dlitt/ (accessed 25 January 2007).

Fals Borda, O. (ed.) (1998). People's Participation: Challenges Ahead, Tercer Mundo Editores, Bogota.

Fals Borda, O. (2006) The North-South convergence. Action Research, 4(3), 351-358.

Fals Borda, O. and Rahman, M. A. (eds) (1991). Action and Knowledge: Breaking the Monopoly with Participatory Action Research, Apex Press, New York.

Freire, P. (1972). Pedagogy of the Oppressed. Penguin, Harmondsworth, UK.

Kiggundu, M. (1991). The challenges of management development in sub-Saharan Africa. Journal of Management Development. 10(6), 42-57.

Lincoln, Y. and Guba, E. (1985). Naturalistic Inquiry, Sage, New York. 
Merriam S. (1988). Case Study Research in Education: A Qualitative Approach, JosseyBass, San Francisco.

Meynell, F. (2005). A second-order approach to evaluating and facilitating organizational change. Action Research. 3(2), 211-231.

Miles, M.B. and Huberman, A.M. (1994). An Expanded Sourcebook of Qualitative Data Analysis (2nd Ed.), Sage, Thousand Oaks, California.

NSDC - National Staff Development Committee (1995). Action Learning in Vocational Education and Training (Volume 1: Theoretical Background), National Staff Development Committee, Commonwealth of Australia, Chadstone VIC.

Patton, M. (1990). Qualitative Evaluation and Research Methods (2 ${ }^{\text {nd }}$ Ed.), Sage, Thousand Oaks, California.

Reed, Y., Davis, H. and Nyabanyaba, T. (2002). Investigating teachers' 'take-up' of reflective practice from an in-service professional development teacher education programme in South Africa. Educational Action Research. 10(2), 253-274.

Revans, R. (1967). Developing a department of business administration in the University of Khartoum. Journal of Management Studies. 4, 169-175.

Revans, R. (1991a). Action learning and the third world. International Journal of Human Resource Management. 1(2), 73-92.

Revans, R. (1991b). Reg Revans speaks about action learning. Video program produced by Ortrun Zuber-Skerritt. University of Queensland, Brisbane: Video Vision, ITS (published on DVD in 2006 by Acaciacom, Brisbane).

Schön, D. A. (1983). The Reflective Practitioner: How Professionals Think in Action, Temple Smith, London.

Senge, P. (1990). The Fifth Discipline, Doubleday/Currency, New York.

Strauss, A. and Corbin, J. (eds) (1997). Grounded Theory in Practice, Sage, Thousand Oakes, California.

Wadsworth, Y. (2005). How can professionals help people to inquire using their own action research?. Action Learning and Action Research (ALAR) Journal. 10(1), 81-82.

Walker, M. (1996). Context, critique and change: Doing action research in South Africa. In O'Hanlon, C. (ed.), Professional Development through Action Research in Educational Settings, Falmer Press, London, pp. 42-60.

Walker, M. and Unterhalter, E. (2004). Knowledge, narrative and national reconciliation: Storied reflections on the South African Truth and Reconciliation Commission. Discourse: Studies in the Cultural Politics of Education. 25(2), 279-297.

Willcox, J. and Zuber-Skerritt, O. (2003). Using Zing team learning system (TLS) as an electronic method for the nominal group technique (NGT). Action Learning and Action Research (ALAR) Journal. 8(1), 59-73.

Yin, R.K. (2003). Case Study Research: Design and Methods ( $3^{\text {rd }}$ ed.), Sage, London.

Zuber-Skerritt, O. (2001). Action learning and action research: Paradigm, praxis and programs. In Sankaran, S., Dick, B., Passfield, R. and Swepson, P. (eds), Effective Change Management Using Action Research and Action Learning: Concepts, Frameworks, Processes and Applications, Southern Cross University Press, Lismore, Australia, pp. 1-20.

Zuber-Skerritt, O. (1996). Action Research for Change and Development (2 ${ }^{\text {nd }}$ ed.), Gower-Avebury, Aldershot, UK. 
Appendix I: Professional development program on action research

\begin{tabular}{|l|l|}
\hline Topic & Issue, activity, approach, method \\
\hline $\begin{array}{l}\text { Action learning } \\
\text { (AL) }\end{array}$ & $\begin{array}{l}\text { Establishing theory: Beliefs, values, philosophical assumptions, } \\
\text { concepts, experiential learning theory, knowledge management } \\
\text { and learning at work; AL roles, processes, strategies, projects, } \\
\text { programs, applications, examples. Video with Reg Revans. } \\
\text { Outcome: Final statements: YOUR definition of AL. }\end{array}$ \\
\hline $\begin{array}{l}\text { Action research } \\
\text { (AR) }\end{array}$ & $\begin{array}{l}\text { Refining terminology: Comparisons between AL and AR; AR } \\
\text { concepts, models, practical applications, examples, problem areas. } \\
\text { Outcome: Final statements: YOUR definition of AR. }\end{array}$ \\
\hline $\begin{array}{l}\text { Philosophy of } \\
\text { science and } \\
\text { fieldwork }\end{array}$ & $\begin{array}{l}\text { Claiming a research position: Research paradigms, } \\
\text { methodologies, qualitative methods of research and evaluation; } \\
\text { knowledge claims and evidence, triangulation, participant } \\
\text { validation, reflection journal. }\end{array}$ \\
\hline $\begin{array}{l}\text { Outcome: YOUR selection and presentation of ONE method to } \\
\text { the whole group (i.e. learning by teaching). }\end{array}$ \\
$\begin{array}{l}\text { Project management } \\
\text { (design, conduct and } \\
\text { evaluation) }\end{array}$ & $\begin{array}{l}\text { Implementation: Socratic approach to project design (and thesis } \\
\text { proposal), checklist; model of strategic planning; team project } \\
\text { design using the AR spiral, enneagram, 'Figure Eight Model', } \\
\text { and/or the 'Change Management Resources Workbook'. } \\
\text { Outcome: YOUR project proposal. }\end{array}$ \\
\hline $\begin{array}{l}\text { Writing a report, } \\
\text { paper/article, thesis } \\
\text { or dissertation }\end{array}$ & $\begin{array}{l}\text { Writing the research: Overview of the research and writing } \\
\text { process; difference between research and writing; focal research } \\
\text { question/problem; structure, mind mapping; assessment criteria, } \\
\text { supportive environment, supervision, examination, } \\
\text { Outcome: YOUR original/new contribution to knowledge } \\
\text { (abstract). }\end{array}$ \\
\hline $\begin{array}{l}\text { Going public: Processes, procedures, ethics; 'publication } \\
\text { syndicates'; selection of appropriate publishers of (ALAR) } \\
\text { journals and books. } \\
\text { Outcome: YOUR publication plan and timetable. }\end{array}$ \\
\hline
\end{tabular}


Appendix II: Summative evaluation report from Stellenbosch University (original)

\section{Workshop Evaluation FEEDBACK REPORT}

Topic: Doing, writing and supervising Action Research

Date: 3 - 5 May 2005

Venue: Protea Hotel

Facilitator: Prof. Ortrun Zuber-Skerritt

Number of participants: 13

Number of Evaluation forms received: 12

Rating: 1 = Poor

$$
\begin{aligned}
& 3=\text { Satisfactory } \\
& 5=\text { Excellent }
\end{aligned}
$$

\begin{tabular}{|c|c|c|c|c|c|c|c|c|}
\hline Category & $\begin{array}{l}\text { No } \\
\text { answer }\end{array}$ & 1 & 2 & 3 & 4 & 5 & Average & $\%$ \\
\hline 1 General organisation & & & & & 3 & 9 & 4.75 & 95 \\
\hline 2 Achievement of goals & & & & & 1 & 11 & 4.91 & 98.2 \\
\hline 3 Level of presentation (only 11 responses) & & & & & 3 & 8 & 4.72 & 94.4 \\
\hline 4 Capability of the facilitator & & & & & & 12 & 5 & 100 \\
\hline 5 Learning gain & & & & & 4 & 6 & 4.6 & 92 \\
\hline 6 Relevance to personal situation (only 11 responses) & & & & 1 & 5 & 5 & 4.36 & 87.2 \\
\hline 7 Potential for implementation & & & & & 3 & 9 & 4.75 & 95 \\
\hline 8 Overall evaluation (only 11 responses) & & & & & 2 & 9 & 4.81 & 96.2 \\
\hline
\end{tabular}

9.1 Topics that need to be emphasised more:

Different methods in Action Learning Techniques

Doing the actual Socratic approach with the workshop leader as well. Especially for future PhD students

Actually doing cycles and examples that fit and that don't fit

Action Research methodology; writing action research

9.2 Topics that need to be emphasised less:

None was mentioned

9.3 Topics that should be left out

None was mentioned 


\subsection{Topics that should be added:}

The video, especially the first part, we should have had the opportunity to listen to it

More time!

How to write up quantitative research results, something that is intimidating when first approached

Writing a real paper on action research to be published

Design of in particular Action Research in depth

\section{Recommendations / Comments}

Divide students/supervisors during some group discussions.

$\Gamma$ I would have liked to see/hear about a project that was started, how it was implemented, problems experienced in the 'true life'.

To be or have practised experience in publishing an action research paper where different methodology have been used with the presenting of results.

Something about what is great. The wonderful resources to use for the future for self and to share with colleagues.

What about making this a 5-day workshop. Adding postgraduate supervision. We did focus on it anyway and it would save an air ticket, etc. for coming to another workshop.

- The strength, patience and expertise of the workshop leader cannot be described. A pity all positivists cannot have come to this workshop to balance their outlook on the different paradigms.

Everything was perfect. Thank you, I appreciate all your efforts. Thanks to Liesl, Ortrun and Chris.

- The video was unfortunately not fit for purpose - we couldn't hear.

An excellent course that could be recommended to all university personnel! Thank you!

- Thank you so much for a fulfilling and well spent meaningful 3 days. You are an inspiration. I learnt so much more than what was covered by the material - thank you for that!

\section{Conclusions and recommendations by facilitators}

Prof. Zuber-Skerritt:

Prof. Zuber-Skerritt is presently in Europe and could not be reached for her comments.

\section{Prof. Kapp:}

As can be seen from the very positive feedback received from the participants, the workshop was an enjoyable and worthwhile experience. This is further validated by the quantitative feedback as reported in 1 to 8 where the ratings on the five categories ranged from 4.36 to 5 and by the qualitative feedback as reported in paragraph 10 .

Our apologies to the facilitator and all the participants for the problems experienced with the video. This unfortunately usually happens when technologies from different continents are not compatible. Our sincere thanks and appreciation to Prof. Zuber-Skerritt for sharing her expertise with us.

\section{Stellenbosch}

12 May 2005 


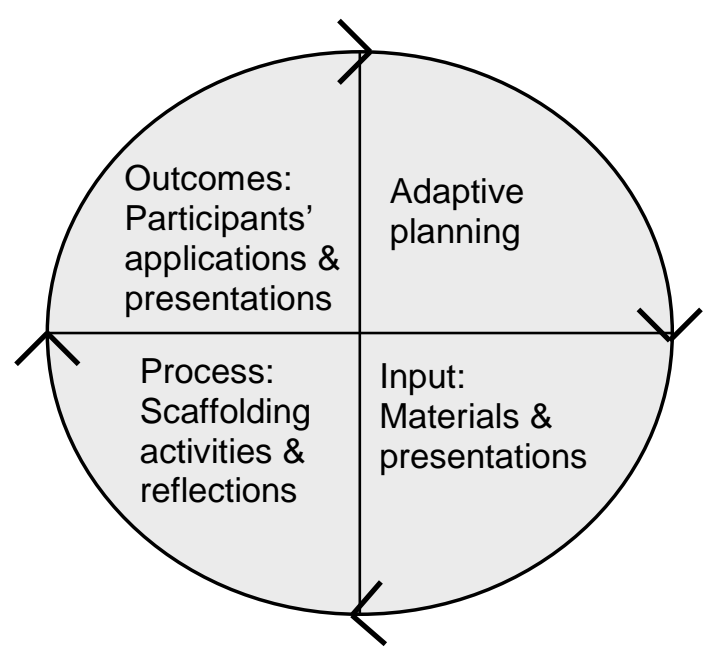

Figure I: Model of workshop cycles of adaptive planning, input, process and output 


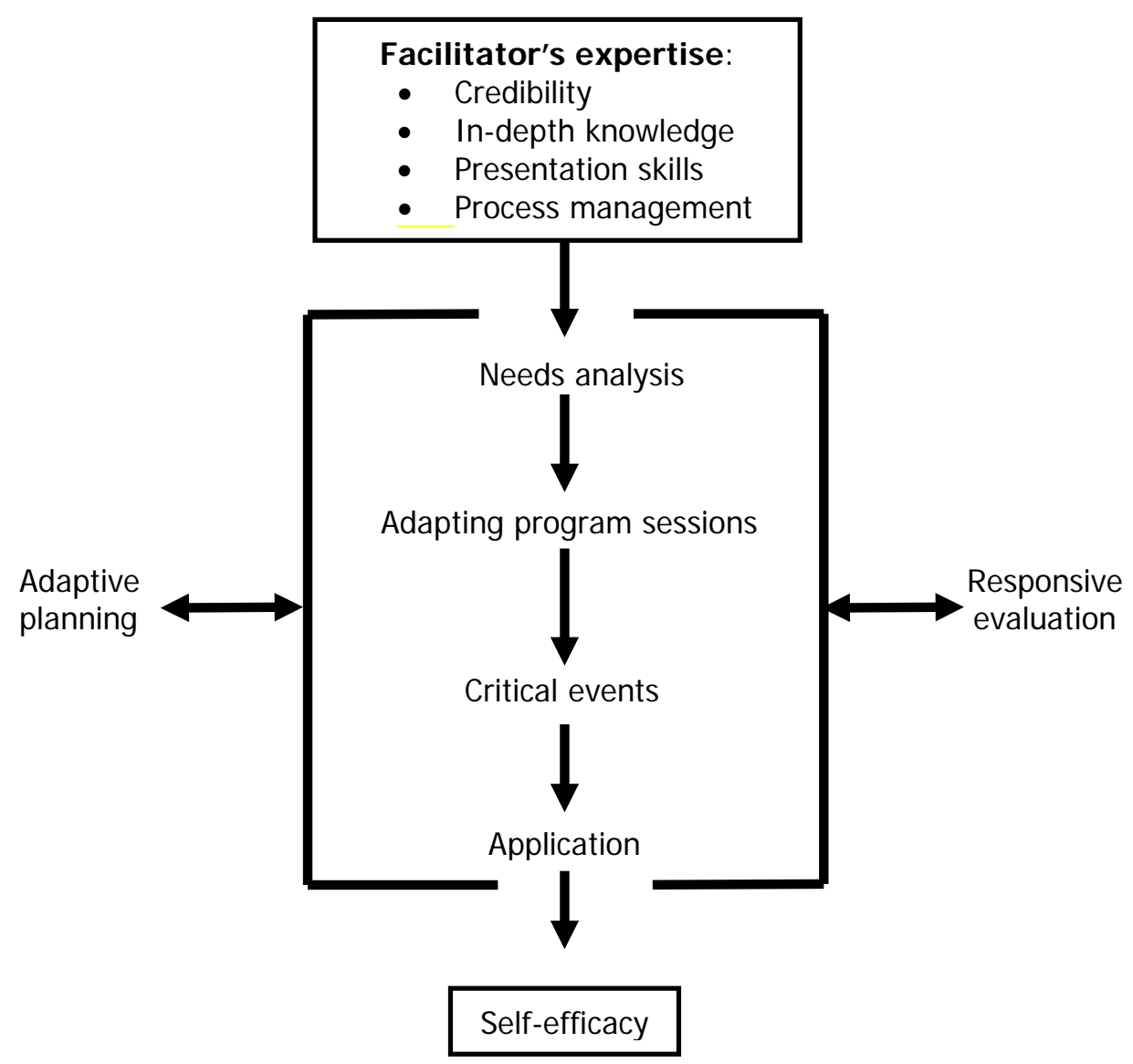

Figure II: Characteristics of a quality professional development program 


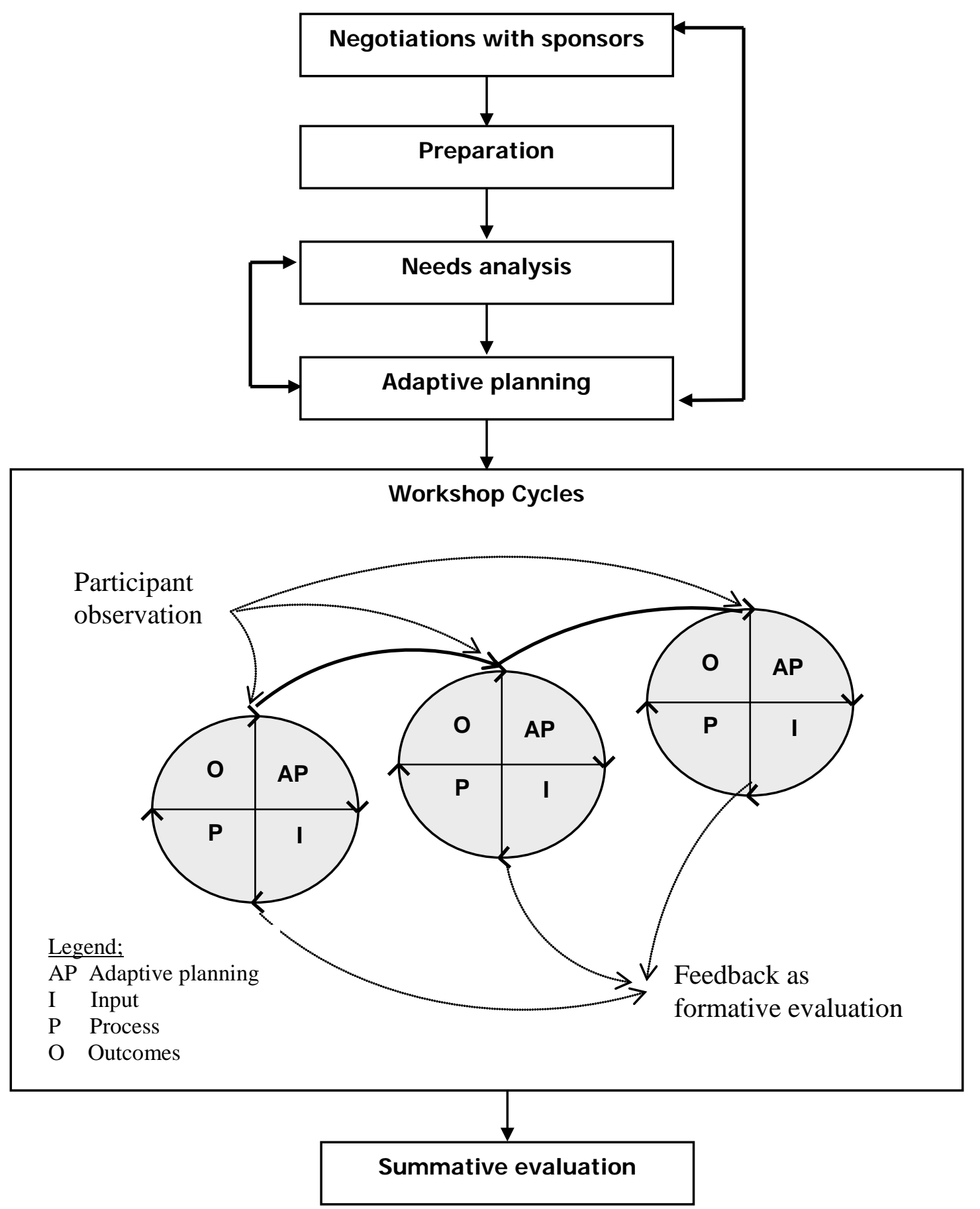

Figure III: A model of a professional development program on and through action research 
Figure IV: A model of the three levels of action research 


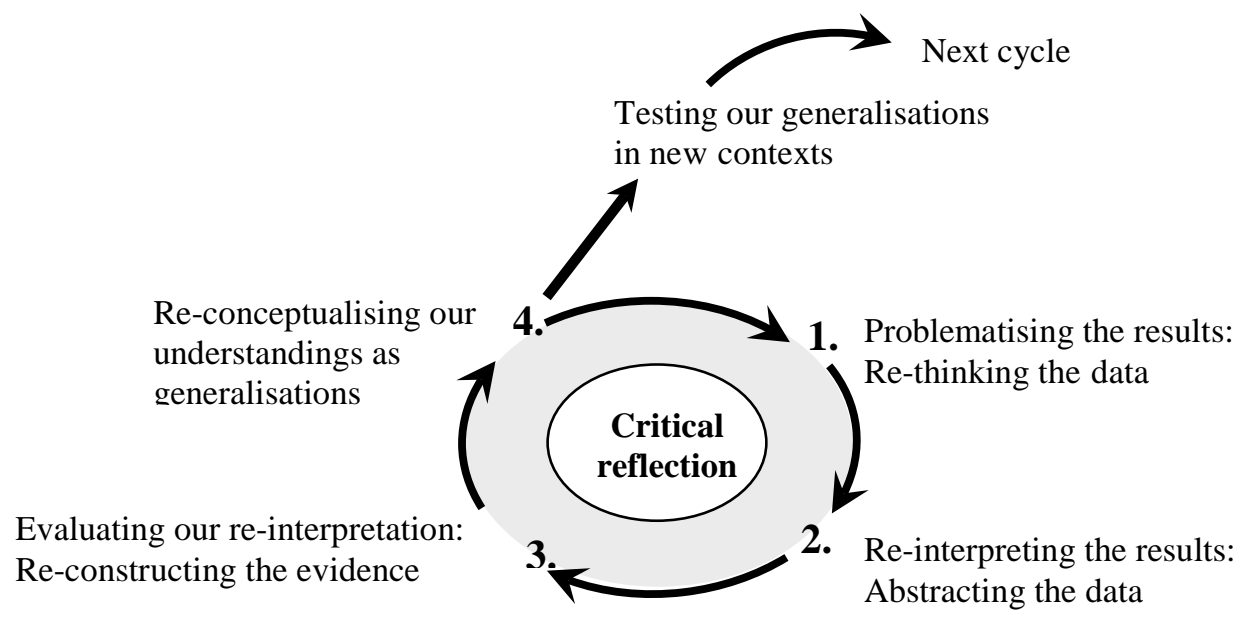

Figure V: A model of meta-action research 